\title{
Screening tests for antibodies to cytomegalovirus: an evaluation of five commercial products
}

\author{
PCA GRINT, CJ RONALDS, HO KANGRO, A CAMPBELL-BENZIE, F WARD, \\ AE HARDIMAN, RB HEATH
}

From the Department of Virology, St Bartholomew's Hospital, London

SUMMARY Four hundred and ninety two samples of serum from blood donors were screened for the presence of antibodies specific to cytomegalovirus using radioimmunoassay, a modified complement fixation test, and five commercially available tests: the Cetus CMV IHA, Abbott CMV total AB EIA, Cytomegalisa Stat EIA, Enzygnost EIA, and Virenz G-CMV EIA. A wide variation in results was found, with only $53.5 \%$ of the sera giving total concordance by all methods. Rates of seropositivity in the different tests ranged from $34.9 \%$ to $59.3 \%$, with sensitivities ranging from $75 \cdot 2 \%$ to $99 \cdot 1 \%$ compared with the radioimmunoassay. Of 211 sera which gave positive results with four or more of the tests, none was negative by the radioimmunoassay and Abbott EIA, three were negative in Cetus IHA and Enzygnost EIA, and 11 were negative in the modified complement fixation test. Virenz $\mathrm{G}$ and Cytomegalisa Stat EIAs, however, gave 40 $(19 \%)$ and $49(23.2 \%)$, respectively, as negative. The results confirmed the reliability of the radioimmunoassay for the detection of the antibody status to $\mathrm{CMV}$, but this test is too elaborate for a screening procedure. The Abbott EIA and Cetus IHA were found to be the most suitable for this purpose in spite of high false positive rates.

It is well known that cytomegalovirus can be transmitted by blood transfusion. Recently, infection with cytomegalovirus has been shown to cause serious complications, especially in neonates receiving exchange transfusions and in patients undergoing bone marrow transplantation.'

No marker is currently available for directly screening donated blood for the presence of cytomegalovirus. Donors can be tested for antibodies to cytomegalovirus indicating past infection with the virus, but this has been shown to correlate positively with the risk of transmitting cytomegalovirus via the donated blood. ${ }^{2}$ Consequently, there is an increasing demand for the screening of blood and blood products destined for specific groups of patients for cytomegalovirus antibody. No generally accepted test, however, for cytomegalovirus antibodies has yet been established. Highly sensitive radioimmunoassays and enzyme immunoassays have been described for the detection of cytomegalovirus antibody, ${ }^{45}$ but these

Accepted for publication 2 May 1985 are not suitable for laboratories lacking the necessary expertise and specialist equipment to perform such tests. Likewise, immunofluorescence techniques have been evaluated, but, for practical reasons, these are generally considered to be unsuitable for screening on a large scale. ${ }^{67}$

Several commercial screening test kits for cytomegalovirus are now available that are primarily aimed at blood transfusion laboratories. It is clear, however, that many of these assays have not been fully evaluated in routine screening practice. We therefore compared the performance of five commercial kits currently available as screening tests for the detection of cytomegalovirus antibodies in 492 blood donors with the complement fixation test and a highly sensitive in-house radioimmunoassay.

\section{Material and methods}

\section{SPECIMENS}

Samples of clotted blood were collected from 492 healthy blood donors over two years. Once in the laboratories the sera were decanted into sterile containers and stored frozen at $-20^{\circ} \mathrm{C}$. 
TESTS

Complement fixation test

A modified complement fixation test was used ${ }^{8}$ to increase sensitivity. The serum and complement were allowed to react for 18 hours at $15^{\circ} \mathrm{C}$ instead of the usual $4^{\circ} \mathrm{C} .{ }^{9}$ For comparative purposes those sera that were positive $(\geqslant 1: 8)$ by this method were further tested by the standard complement fixation method. In both methods commercial cytomegalovirus complement fixation and control antigens (Hoechst UK Ltd) were used at the same dilution.

\section{Radioimmunoassay}

The assay used was an indirect solid phase radioimmunoassay, which had been developed and evaluated in the department. ${ }^{510}$ Fifty $\mu$ l aliquot of test serum diluted $1 / 100$ and 1/400 were added to duplicate microtitre wells containing cytomegalovirus or control antigens (Hoechst UK Ltd) identical to those used in the modified complement fixation test. After incubation at $37^{\circ} \mathrm{C}$ for 150 minutes the plates were washed three times and $50 \mu$ l of ${ }^{125} \mathrm{I}$-labelled goat antihuman IgG (Tago), containing about 40000 counts/minute, was added to each well. After further incubation at $37^{\circ} \mathrm{C}$ for 60 minutes the plates were washed 15 times and the radioactivity that had been bound in individual wells was counted in an NE1600 gamma counter (Nuclear Enterprises Ltd). A binding ratio, obtained by dividing the mean counts per minute for each dilution of serum by the background radioactivity, was determined. The virus specific binding index for each sample of serum was calculated by dividing the binding ratio with viral antigen by the binding ratio with control antigen. A specific binding index of over 2 , at either dilution of serum, was taken to indicate the presence of virus specific antibody.

\section{Commercial cytomegalovirus antibody tests}

The commercial test kits assessed were an indirect haemagglutination assay, Cetus cytomegalovirus IHA (Diamed Diagnostics Ltd), and four enzyme immunoassays (EIA): Abbott CMV total AB EIA (Abbott Laboratories); Cytomegalisa Stat (MA Bioproducts supplied by Laboratory Impex Ltd); Enzygnost EIA (Hoechst UK Ltd), and Virenz G-CMV EIA (Northumbria Biologicals Ltd). Each test was performed strictly in accordance with the manufacturer's instructions.

The absorbance values for the Virenz G, Enzygnost, and Cytomegalisa Stat tests were determined using a Titertek Multiskan Photometer type 310C. The absorbance values for the Abbott EIA were determined using a Quantum II analyser, on loan from Abbott Laboratories. Results considered to be borderline by any test method were retested in accordance with the manufacturer's recommenda- 으 tions. Test sensitivity, specificity, and accuracy were calculated as described by Griner et al. ${ }^{11}$ The test procedures for each kit were, briefly, as follows:

Cetus $I H A$ A $50 \mu$ l volume of a 1/4 dilution of $\frac{}{\sigma}$ serum was pipetted in to each of two wells in a " $\mathrm{V}$ " $\overline{\frac{\bar{\sigma}}{\sigma}}$ well microtitre plate. Twenty five $\mu$ of $\underset{\mathbb{D}}{ }$ cytomegalovirus test cells were added to one well and the same volume of control cells added to the second well. The tests were read after a minimum $\overrightarrow{0}$ incubation time of 90 minutes at room temperature. $\overrightarrow{\vec{\omega}}$ The detection of cytomegalovirus specific antibody was indicated by the presence of partial or complete agglutination in the test well and its absence in the control well.

Abbott EIA Ten $\mu$ l of serum was added to $200 \mu \mathrm{l}$ of serum diluent in a well of a reaction tray. A polystyrene bead coated with cytomegalovirus antigen was added to each well. The trays were incubated at $40^{\circ} \mathrm{C}$ for 60 minutes and the beads were washed. $\vec{c}$ Two hundred $\mu$ l of horseradish peroxidase conju- $\mathbb{\Phi}$ gated goat antihuman immunoglobulin was added $\frac{\bar{D}}{\mathbb{D}}$ and the trays were reincubated for 30 minutes. After $\frac{D}{3}$ washing the beads were transferred to individual $\underset{\mathbb{D}}{\bar{D}}$ assay tubes. Three hundred $\mu \mathrm{l}$ of $\mathrm{O}-\frac{\overrightarrow{ }}{\circ}$ phenylenediamine hydrochloride substrate was added and the tubes were left for 30 minutes room temperature. The reaction was halted by the addition of $1 \mathrm{ml}$ of $1 \mathrm{~N} \mathrm{H}_{2} \mathrm{SO}_{4}$ and the absorbance was then read at $492 \mathrm{~nm}$. Test specimens with absorbance values equal to or greater than the cut

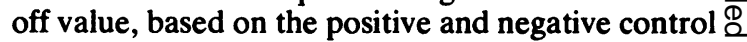
sera supplied, were denoted reactive for antibody to $\overrightarrow{\bar{O}}$ cytomegalovirus.

Virenz $G E I A$ One hundred $\mu$ l of a 1/50 dilution of $\vec{z}$ test serum was added to a microtitration well coated with cytomegalovirus antigen, with a further $100 \mu \mathrm{l}$ aliquot added to an adjacent uncoated control well. After incubation at room temperature for $30 \frac{5}{3}$ minutes the wells were washed and $100 \mu$ l of horseradish peroxidase conjugated swine antihuman IgG added. After further incubation for one hour at room temperature and subsequent washing $100 \mu \mathrm{l}$ 을 of substrate $3,3^{\prime}, 5,5^{\prime}$ tetramethyl benzidine was added. The colour change was allowed to develop을. for 30 minutes at room temperature, halted by the $\mathrm{N}$ addition of $100 \mu$ lof $5 \mathrm{~N} \mathrm{H}_{2} \mathrm{SO}_{4}$ and the absorbance read at $450 \mathrm{~nm}$. Sera, giving a corrected absorbance $\mathrm{N}$ value (value of well coated with cytomegalovirus $\omega$ minus value of control well) greater than that of the low positive control serum, were considered positivece for cytomegalovirus specific antibody.

Enzygnost EIA One hundred and fifty $\mu$ l volumes: of serum diluent were dispensed into wells coated $T$ with cytomegalovirus and control antigen. Fifty $\mu$ l of $\frac{\vec{\Phi}}{\vec{\Phi}}$ 
a 1/11 dilution of serum was then added to both wells. The test plate was incubated for 60 minutes at $37^{\circ} \mathrm{C}$ and then washed. Fifty $\mu$ l of alkaline phosphatase conjugated rabbit antihuman IgG was added and the plates were reincubated for 60 minutes at $37^{\circ} \mathrm{C}$ and washed. One hundred $\mu \mathrm{l}$ of p-nitrophenyl phosphate substrate was added with a further incubation of 30 minutes at $37^{\circ} \mathrm{C}$. The enzyme reaction was halted by the addition of $50 \mu \mathrm{l}$ of $2 \mathrm{~N}$ sodium hydroxide and the absorbance values were read at $405 \mathrm{~nm}$. Sera were considered cytomegalovirus antibody positive if the differences in absorbance values between the test and control wells was $\geqslant 0.2$ absorbance units.

Cytomegalisa Stat EIA Five $\mu$ l of test serum was mixed with $100 \mu \mathrm{l}$ of serum diluent in a test and control well coated with antigen and incubated for 15 minutes at room temperature on a plate shaker. After washing $100 \mu \mathrm{l}$ of alkaline phosphatase conjugated rabbit antihuman IgG was added and the "removawell" plate was reincubated for 15 minutes at room temperature on the plate shaker. After washing $100 \mu \mathrm{l}$ of phenolphthalein monophosphate substrate solution was added and the colour change developed at room temperature for 15 minutes on the plate shaker. The reaction was halted by the addition of $200 \mu \mathrm{l} 0 \cdot 1 \mathrm{~N}$ sodium hydroxide. Absorbance values were read at $550 \mathrm{~nm}$. A positive test result was defined as an absorbance value equivalent to or greater than the mean absorbance value of the two low positive serum controls provided.

\section{Results}

Table 1 shows the results of the tests. Two hundred and sixty three $(53.5 \%)$ of the 492 sera tested gave concordant results by all test methods, 116 sera were positive, and 147 sera negative. The prevalence of cytomegalovirus antibody by the different tests ranged from $34.9 \%$ in the cytomegalisa stat EIA, to $59.3 \%$ in the cetus IHA. On the basis of the proportion of positive results, the tests can broadly

Table 1 No of positive and negative sera obtained by each test method

\begin{tabular}{lll}
\hline & $\begin{array}{l}\text { Positive \% } \\
(n=492)\end{array}$ & Negative \% \\
\hline Radioimmunoassay & $214(43 \cdot 5)$ & $278(56 \cdot 5)$ \\
Modified CF test & $204(41 \cdot 5)$ & $288(58 \cdot 5)$ \\
Cetus IHA & $292(59 \cdot 3)$ & $200(40 \cdot 7)$ \\
Abbott EIA & $261(53 \cdot 1)$ & $231(46 \cdot 9)$ \\
Virenz G EIA & $188(38 \cdot 2)$ & $304(61 \cdot 8)$ \\
$\begin{array}{l}\text { Enzygnost EIA } \\
\text { Cytomegalisa Stat EIA } 172(34 \cdot 7)\end{array}$ & $277(56 \cdot 3)$ \\
$\begin{array}{l}\text { Concordant by all } \\
\text { methods }\end{array}$ & $116(23 \cdot 6)$ & $320(65 \cdot 1)$ \\
\hline
\end{tabular}

*Includes 83 sera showing reaction with Cetus IHA control cells. be divided into three groups: the Cytomegalisa Stat and Virenz G EIAs detected as positive less than $40 \%$ of the sera; radioimmunoassay, modified complement fixation, and Enzygnost EIA detected between $41.5 \%$ and $43.7 \%$; and the Abbott EIA and Cetus IHA gave $>50 \%$ of the sera as positive.

\section{Modified complement fixation and radioimmunoas-} say

When the modified complement fixation and radioimmunoassay procedures routinely used in this laboratory were compared $474(96.3 \%)$ of the sera gave concordant results (Table 2). Of the 18 discordant sera 14 were positive in the radioimmunoassay but negative in the modified complement fixation. Eleven of these 14 sera also gave positive results in three or more of the commercial assays, providing supporting evidence for the presence of cytomegalovirus specific antibody in these samples. Table 3 shows the reaction profiles of the remaining three sera (nos 10,133, and 439). These sera gave very weak positive results in radioimmunoassay and were positive by only one other test method: possibly, these were false positive radioimmunoassay results. Similarly, the four modified complement fixation positive but radioimmunoassay negative sera were reactive only in a maximum of two other tests, Cetus IHA or Abbott EIA, or both, the Cetus IHA results showing agglutination of control cells and, therefore, probably not genuinely positive for cytomegalovirus specific antibody.

The 204 modified complement fixation positive sera were also tested using the conventional method of incubation overnight at $+4^{\circ} \mathrm{C}$. Of these, only 150 $(73 \%)$ were positive at a $1 / 4$ dilution, showing the lower sensitivity of this method. Clearly, of the three established in house techniques, the radioimmunoassay was the most sensitive for screening purposes. Consequently, the performance of each commercial assay was compared with that of the radioimmunoassay (Table 2 ).

Comparing each of the tests against the others, we found that radioimmunoassay showed the best agreement. No sera were identified as antibody positive or negative by the radioimmunoassay alone, in contrast to the other assays, and only three RIA positive sera (Table 3 ) were positive in less than three other tests. Conversely, only three of the radioimmunoassay negative sera were positive by a maximum of three other tests. If a concordance in at least four of the seven tests is accepted as indicative of the presence of cytomegalovirus specific antibody then the sensitivity and specificity of the radioimmunoassay were $100 \%$ and $98.9 \%$, respectively; the overall agreement of the radioimmunoassays with the other tests was then $99.4 \%$. 
Table 2 Comparison of results obtained by modified complement fixation and commercial tests with corresponding radioimmunoassay results

\begin{tabular}{|c|c|c|c|c|c|}
\hline & \multicolumn{2}{|c|}{ Radioimmunoassay positive sera } & \multicolumn{2}{|c|}{ Radioimmunoassay negative sera } & \multirow{2}{*}{$\begin{array}{l}\text { Total concordance with } \\
\text { radioimmunoassay }\end{array}$} \\
\hline & Test positive & Test negative & Test positive & Test negative & \\
\hline $\begin{array}{l}\text { Modified CF test } \\
\text { Cetus IHA } \\
\text { Abbott EIA } \\
\text { Virenz G EIA } \\
\text { Enzygnost EIA } \\
\text { Cytomegalisa Stat EIA }\end{array}$ & $\begin{array}{l}200 \\
183(+27)^{*} \\
212 \\
171 \\
207 \\
161\end{array}$ & $\begin{array}{r}14 \\
4 \\
2 \\
43 \\
7 \\
53\end{array}$ & $\begin{array}{l}4 \\
26(+56)^{*} \\
49 \\
17 \\
8 \\
11\end{array}$ & $\begin{array}{l}247 \\
196 \\
229 \\
261 \\
270 \\
267\end{array}$ & $\begin{array}{l}96.3 \% \\
93.1 \% * *(82 \cdot 5 \%) \\
89.6 \% \\
87 \cdot 8 \% \\
97 \cdot 0 \% \\
87.0 \%\end{array}$ \\
\hline
\end{tabular}

*Figures in brackets are sera that showed agglutination of Cetus IHA control cells.

** Concordance excluding sera that showed agglutination of Cetus IHA control cells.

Table 3 Test results obtained with three radioimmunoassay positive sera, which gave positive results in only one other test

\begin{tabular}{|c|c|c|c|c|c|c|c|}
\hline Serum No & Radioimmunoassay & Modified CF test & Cetus IHA & Abbott EIA & Virenz $G E I A$ & $\begin{array}{l}\text { Enzygnost } \\
\text { EIA }\end{array}$ & $\begin{array}{l}\text { Cytomegalisa } \\
\text { Stat EIA }\end{array}$ \\
\hline 10 & + & - & + & - & - & - & - \\
\hline 133 & + & $\overline{-}$ & + & $\overline{1}$ & - & - & - \\
\hline 439 & + & & - & + & - & - & - \\
\hline
\end{tabular}

\section{CETUS IHA}

The interpretation of the results obtained by the Cetus IHA test is complicated by the fact that, altogether, 83 sera reacted with control cells of which $27(32.5 \%)$ were positive and $56(67.5 \%)$ negative by radioimmunoassay. As stated by the manufacturer, the immune status of such samples cannot be determined by the Cetus IHA procedure. When screening without access to confirmatory tests, these sera would have to be regarded as positive. If these sera are excluded from the calculations the concordance between Cetus IHA and radioimmunoassay was very good, $93 \cdot 1 \%$ (Table 2 ). Excluding those with non-specific reactivity, 26 sera were radioimmunoassay negative and Cetus IHA positive. Of these, $15(57.7 \%)$ were positive by Cetus IHA alone, with nine of the remaining 11 being positive in only one other test, the Abbott EIA in all cases. Four sera were radioimmunoassay positive but Cetus IHA negative and three of these positive in three or more other tests.

\section{ABBOTT EIA}

Altogether $51(10.4 \%)$ of the sera gave discordant results in the Abbott EIA and radioimmunoassay. Only two of the radioimmunoassay positive sera (Nos 10 and 133, Table 3) were negative in the Abbott EIA, but 49 of the radioimmunoassay negative sera were positive. Of these, $26(53.1 \%)$ were positive in the Abbott EIA alone and 18 also positive in one other test, 14 in the Cetus IHA, including six sera, which reacted with the control cells. The remaining five sera were positive in two other tests. Notably, $28(57 \cdot 1 \%)$ of these 49 sera showed reac- tivity with control antigens in the assay systems in which these were used.

\section{VIRENZ G EIA}

This test correlated poorly with the radioimmunoase say (Table 2), mainly due to 43 sera which were RIA positive but Virenz $G$ negative. Forty of these sera were positive in three or more other tests; the remaining samples were Nos 10, 133, and 439 (Table 3). Seventeen sera were Virenz G EIA positive but radioimmunoassay negative; of these, 12 were positive by Virenz G EIA alone and four of the five remaining sera only positive by Cetus IHA, including three sera, which reacted with the control cells in this assay.

ENZYGNOST EIA

The correlation between this test and the radioimmunoassay was very good (97\%, Table 2$)$. Seven sera were radioimmunoassay positive but Enzygnost EIA negative. Three of these sera were positive in three or more other tests. Eight sera were Enzygnost EIA positive but radioimmunoassay negative and of these, two were positive by two other methods, four by one method, and two were positive in the Enzygnost assay alone.

CYTOMEGALISA STAT EIA

This test gave the lowest proportion of positive $\underset{\gamma}{ }$ results. In fact, 53 of the radioimmunoassay positive $\theta$ sera were negative by Cytomegalisa Stat EIA. Of $\frac{\bar{\Phi}}{\mathbb{}}$ these, $49(92.5 \%)$ were positive in three or more $\stackrel{\infty}{+}$ other tests and three of the remaining four sera are shown in Table 3. Eleven sera were radioimmunoas- 
say negative but Cytomegalisa Stat EIA positive. Six of these, however, were positive by Cytomegalisa Stat EIA alone, and four were positive in only one other test, including two sera which reacted with the control cells in the Cetus IHA.

\section{Comparative sensitivity}

In addition to the results described, a further experiment was performed to assess the comparative sensitivity of the assays. A doubling dilution series of cytomegalovirus low positive (modified complement fixation titre 1/32) serum in negative serum was made. Five replicates of each dilution, considered as neat serum samples, were subsequently tested in each assay system as previously described. Table 4 shows the results. The radioimmunoassay and Cetus IHA proved to be the most sensitive tests, followed by the Enzygnost and Abbott EIAs. Virenz G and modified complement fixation tests were the least sensitive; 16-32-fold lower than radioimmunoassay and Cetus IHA.

\section{Discussion}

The main problem encountered in studies to evaluate screening tests for antibodies to cytomegalovirus is the absence of a recognised reference test. When several different tests are compared discordant results must be expected with some sera, but at present no definitive assessment can be made of the true antibody status of such serum samples. When tests are to be used for screening large numbers of blood donors to identify those who are seropositive for CMV antibody a high level of sensitivity of the assays is the prime consideration. If this is gained at the expense of the specificity the result will be the exclusion from use of some units of cytomegalovirus seronegative blood, although this may be acceptable.

Of the tests included in this study, the Cetus IHA and Abbott EIA tests gave the highest proportion of positive results-more than $50 \%$ of those tested. In the Cetus IHA the positivity rate is artificially inflated by the large number $(17 \cdot 3 \%)$ of sera that reacted with control cells. This high proportion of reactive sera may in part have been due to the initial freezing and thawing of the stored sera, which has been shown to increase control cell reactivity in the Cetus IHA. ${ }^{1213}$ Even disregarding the control reactive sera, the Cetus IHA gave $>50 \%$ of the sera as positive. Of the sera classified as positive in the Abbott EIA, $17.6 \%$ were judged to be false positive in comparison with the radioimmunoassay. This may be explained in part by the lack of a control antigen in this test. In fact, $57 \%$ of these false positive sera showed reactivity with control antigen in other assays, compared with $21 \%$ of the sera deemed to be true positives.

The chance of wrongly classifying truly antibody positive sera must also be considered. Even in this respect the Cetus IHA and Abbott EIA performed well (Table 5), with sensitivities of $>98 \%$ compared with the radioimmunoassay. If the performance of the tests is assessed with reference to the concordance of the other tests then the Virenz $G$ and Cytomegalisa Stat EIAs failed to detect $19 \%$ and $23.2 \%$, respectively, of the sera that were positive in four or more tests. By comparison, the radioimmunoassay, Abbott and Enzygnost EIAs, and Cetus IHA failed to detect $<1.4 \%$, with the modified complement fixation test not detecting $5.2 \%$ of these sera. When using a test for diagnostic purposes or to determine the immune status of a patient, the assay must be not only highly sensitive but also highly specific. Notably, the tests with the best specificity were those in which a control antigen was included (Table 5). Comparing all the tests, using the above criteria, radioimmunoassay was shown to be the most reliable test with only three false positive and no false negative results. Of the commercial tests, the Enzygnost EIA performed best in comparison with radioimmunoassay (Table 5).

Consideration was also given to other factors relevant to the selection of a suitable screening test. Notably, there was little or no compatibility of the microtitration plastic supplied in the kits, which led to difficulty when attempting to use equipment and hardware from different manufacturers.

Table 4 Screening of dilutions known to contain cytomegalovirus antibodies by seven assay techniques

\begin{tabular}{|c|c|c|c|c|c|c|c|c|}
\hline & \multicolumn{8}{|c|}{ Replicates of prediluted sera* giving positive results $(n=5)$} \\
\hline & $1: 2$ & $1: 4$ & $1: 8$ & $1: 16$ & $1: 32$ & $1: 64$ & $1: 128$ & $1: 256$ \\
\hline $\begin{array}{l}\text { Radioimmunoassay } \\
\text { Modified CF test } \\
\text { Cetus IHA } \\
\text { Abbott EIA } \\
\text { Virenz G EIA } \\
\text { Enzygnost EIA } \\
\text { Cytomegalisa Stat EIA }\end{array}$ & $\begin{array}{l}5 \\
5 \\
5 \\
5 \\
4 \\
5 \\
5\end{array}$ & $\begin{array}{l}5 \\
5 \\
5 \\
5 \\
4 \\
5 \\
5\end{array}$ & $\begin{array}{l}5 \\
0 \\
5 \\
5 \\
1 \\
5 \\
5\end{array}$ & $\begin{array}{l}5 \\
0 \\
5 \\
5 \\
0 \\
5 \\
4\end{array}$ & $\begin{array}{l}5 \\
0 \\
5 \\
5 \\
0 \\
2 \\
0\end{array}$ & $\begin{array}{l}4 \\
0 \\
5 \\
0 \\
0 \\
0\end{array}$ & $\begin{array}{l}3 \\
0 \\
5 \\
0 \\
0 \\
0 \\
0\end{array}$ & $\begin{array}{l}0 \\
0 \\
0 \\
0 \\
0 \\
0 \\
0\end{array}$ \\
\hline
\end{tabular}

*These were further diluted for each test according to manufacturers' instructions. 
Table 5 Performance values for commercial assays and modified complement fixation test compared with corresponding radioimmunoassay expressed as a percentage

\begin{tabular}{lcccccc}
\hline & Modified CF test & Cetus IHA & Abbott EIA & Virenz G EIA & Enzygnost EIA & $\begin{array}{l}\text { Cytomegalisa Stat } \\
\text { EIA }\end{array}$ \\
\hline Accuracy & 96.3 & 82.5 & 89.6 & 87.8 & 97.0 & 87.0 \\
Sensitivity & 93.5 & 98.1 & 99.1 & 79.9 & 96.7 & 75.2 \\
Specificity & 98.6 & 70.5 & 82.4 & 93.9 & 97.1 & 96.0 \\
False positivity & 1.4 & 29.5 & 17.6 & 6.1 & 2.9 & 4.0 \\
False negativity & 6.5 & 1.9 & 0.9 & 20.1 & 3.3 & 24.8 \\
\hline
\end{tabular}

Performance values calculated according to Griner et al."

In general, the commercial kits were found to be simple to use, although the Enzygnost EIA is, if used as a screening test, somewhat intricate in its present form, and the accompanying instructions are difficult to follow. This particular assay is relatively expensive and the reagents are not marketed in kit form. In the Cytomegalisa Stat EIA technical difficulties were encountered with the poorly fitting plastic "removawell" system. A further factor of importance to laboratories relying on commercial tests is the possible batch variation of the products. This aspect, however, was outside the scope of the present study.

With all the test kits, results can be obtained within three to four hours. An advantage of the Cetus IHA test is that the test plates can be retained for up to 18 hours whereas in the enzyme immunoassays the results have to be read within one to two hours.

The preliminary work necessary to establish the radioimmunoassay is considerable and requires designated radioisotope facilities, which may not be available in all laboratories. The test is also labour intensive to perform and therefore unsuitable as a screening procedure. The incubation time of 18 hours for the modified complement fixation test precludes it as a screening procedure in many instances. Nevertheless, the modified complement fixation test could be considered when results obtained on the same day are not essential.

From the results of this study, the Cetus IHA and Abbott EIA would seem to be the tests best suited for screening purposes. The testing of the sera in the Abbott EIA is considerably aided by semiautomation, using the spectrophotometer and the equipment for bead washing supplied by the manufacturers. On the other hand, the Cetus IHA is simple to use and does not require specialised equipment; micro adaptations have been described ${ }^{6 / 4}$ and if a similar level of sensitivity is maintained in these adaptions this could seem to be a test which is well suited for laboratories lacking the facilities for enzyme immunoassays.

In conclusion, we found a significant variation in the sensitivity of the different assays available, which must be a cause of concern to those considering the use of a commercial kit for the screening for antibodies to cytomegalovirus. We regard this considerable variation in performance as a serious prob- lem requiring immediate attention. At present, no licencing or national reference system exists to define minimum standards for such commercial products-shortcomings which must be remedied.

\section{References}

' Ho M. Cytomegalovirus: biology and infection. New York: Plenum, 1982.

2 Yeager AA, Grumet FC, Hatleigh EB, Arvin, AM, Bradley JS, Prober CG. Prevention of transfusion-acquired cytomegalovirus infections in newborn infants. $J$ Pediatr 1981;98:281-7.

${ }^{3}$ Monif GRG, Diacoff GI, Flory LL. Blood as a potential vehicle for the cytomegalovirus. Am J Obstet Gynecol 1976; 126:445-8.

${ }^{4}$ Kangro HO. Evaluation of a radioimmunoassay for IgM class antibodies against cytomegalovirus. $\mathrm{Br} J$ Exp Pathol 1980; 61:521-30.

$s$ Booth JC, Hannington G, Bakir TMF, et al. Comparison of enzyme-linked immunosorbent assay, radioimmunoassay of complement fixation, anticomplement immunofluorescence. and passive haemagglutination techniques for detectiff cytomegalovirus IgG antibody.J Clin Pathol 1982;35:1345-8.

- Hunt AF, Allen DL, Brown RL, Robb BA, Puckett AY, Entwhistle CC. Comparative trial of six methods for the detection of CMV antibody in blood donors. J Clin Pathol 1984;37:95-7.

${ }^{7}$ Kline WE, Bowman RJ, Balfour HH. Edelman CK, Hockinson BK. Appraisal of enzyme-linked immunoassay (ELISA) and Immunohaemagglutination (IHA) CMV test methods for blood donor screening. Transfusion 1983;23:418.

${ }^{8}$ Ronalds CJ, Hardiman AE, Griffiths PD. Hotting-up the complement fixation test. J Hyg (Camb) 1983;90:127.

${ }^{4}$ Griffiths PD, Buie KJ, Heath RB. A comparison of complement fixation, indirect immunofluorescence for viral late antigens, and anti-complement immunofluorescence tests for the detection of cytomegalovirus specific serum antibodies. J Clin Pathol 1978;31:827-31.

${ }^{10}$ Kangro HO, Griffiths PD, Huber TJ, Heath RB. Specific IgM class antibody production following infection with cytomegalovirus. J Med Virol 1982;10: 203-12.

" Griner PF, Mayewski RJ, Mushlin AI, Greenland P. Selection and interpretation of diagnostic tests and procedures. Ann Intern Med 1981;94:553-600.

${ }^{12}$ Brandt JA, Kettering JD, Lewis JE. Immunity to human cytomegalovirus measured and compared by complement fixation, indirect fluorescent-antibody, indirect haemagglutination, and enzyme-linked immunosorbent assays. J Clin Microbiol 1984; 19: 147-52.

${ }^{13}$ Nuttall PA. Cytomegalovirus (CMV) screening - a view from a regional transfusion centre. Diamed Diary (Diamed Diagnostics Ltd) 1984; Issue 2.:

${ }^{14}$ Henry SM, Ramirez AM, Woodfield DG. Micromodified cytomegalovirus antibody screening test. J Clin Pathol 1985;38: 111-3.

Requests for reprints to: Dr PCA Grint, Virology Department, St Bartholomew's Hospital, London EC1A 7BE, 을 England. 